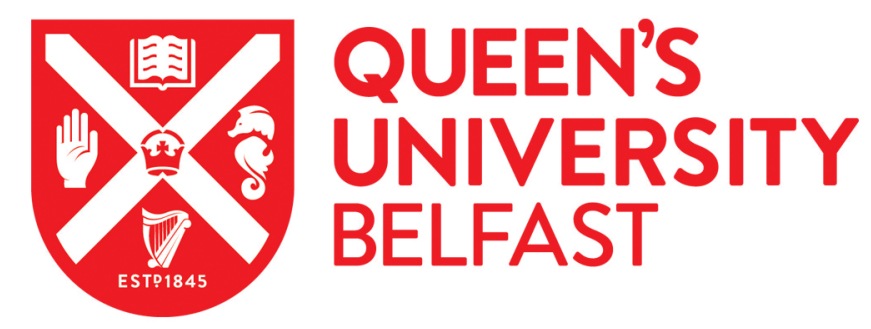

\title{
A Cluster Randomised Controlled Trial of "Bookstart+": A Book Gifting Programme
}

O'Hare, L., \& Connolly, P. (2014). A Cluster Randomised Controlled Trial of "Bookstart+": A Book Gifting Programme. Journal of Children's Services, 9(1), 18-30. [17106645]. https://doi.org/10.1108/JCS-05-2013-0021

Published in:

Journal of Children's Services

Document Version:

Peer reviewed version

Queen's University Belfast - Research Portal:

Link to publication record in Queen's University Belfast Research Portal

Publisher rights

This is an accepted version of an article published here: http://www.emeraldinsight.com/doi/abs/10.1108/JCS-05-2013-

0021 ?journalCode=jcs

\section{General rights}

Copyright for the publications made accessible via the Queen's University Belfast Research Portal is retained by the author(s) and / or other copyright owners and it is a condition of accessing these publications that users recognise and abide by the legal requirements associated with these rights.

Take down policy

The Research Portal is Queen's institutional repository that provides access to Queen's research output. Every effort has been made to ensure that content in the Research Portal does not infringe any person's rights, or applicable UK laws. If you discover content in the Research Portal that you believe breaches copyright or violates any law, please contact openaccess@qub.ac.uk. 


\section{A Cluster Randomised Controlled Trial of 'Bookstart+': A Book gifting Programme}

\section{Structured Abstract:}

Purpose

The purpose of this study was to evaluate the effectiveness of a free book gifting programme, called 'Bookstart+', in improving family reading outcomes.

Design and methodology

Bookstart+ consists of a pack of books and reading materials provided to families at their two year old child's statutory health visit. The pack is accompanied by a short priming demonstration, delivered by the health visitor, on shared reading. The evaluation took the form of a randomised controlled trial (RCT) with 460 families from the client lists of 115 health visitors.

\section{Findings}

The study found evidence of: a positive significant effect on parents' attitudes to reading and books (Cohen's $d=+.192, p=.034$ ); no significant effect on parental attitudes to their child reading $(d=+.085, p=.279)$; and a negative effect, approaching significance, on public library usage $(d=-.160, p=.055)$.

\section{Research limitations/implications}

The attrition rate was high with only $43.9 \%$ of the target families completing all of the research. However, this level of attrition did not lead to any significant differences between the control and intervention groups on their pre-test measures.

\section{Practical implications}

The study provides recommendations for free book gifting service provision in relation to pack contents and delivery.

\section{Originality/value}

This paper contributes to the limited international RCT evidence on free book gifting programmes. 


\section{Introduction}

The implementation of free book gifting programmes is a growing international occurrence. In general, free book gifting programmes aim to encourage shared reading practices at home, which have been linked to several positive outcomes for children and their families including: promoting literacy skills; encouraging positive attitudes to reading; acquiring knowledge and improving emotional relationships between carers and their children (Bus et al., 1995).

Internationally, there are two major book gifting organisations whose primary activity is providing free books to families, namely: Booktrust; and Dolly Parton's Imagination Library. Booktrust is an independent UK Charity that has been delivering free book gifting interventions for over 20 years. It delivers a range of programmes to different age groups and specific populations of children. Its programmes are generally co-funded by the UK Government and publishing companies. Historically, Booktrust has delivered several different universal and targeted programmes that present age appropriate books at different developmental stages. These programmes have been: Bookstart (for children aged one); Bookstart+ (for children aged two); Treasure Chest (for pre-school children); Booktime (for children in their first year of primary school); Booked Up (for children in their first year of secondary education); and the Letterbox Club, (gifted monthly to children in care). Dolly Parton's Imagination Library typically delivers an age-appropriate, free hardcover book every month to registered children, from birth until age five. The programme currently operates in the United States, Canada and United Kingdom and is generally funded by communities and/or individuals through fundraising activities.

The following article presents the findings of an independent randomised controlled trial evaluation of the Bookstart+ programme. The programme is an intervention provided by health visitors in the UK on behalf of Booktrust. Bookstart+ has two main elements. The first is the provision of a set of books and associated reading materials which are presented by a health visitor on their statutory visit to families with a two-year-old child. Furthermore, the health visitor has been trained to provide a demonstration of the pack in relation to how it can be used by parents to read with their two-year-old child.

\section{The Effectiveness of Free Book Gifting and Shared Reading Interventions}

Several studies have shown shared reading interventions to have beneficial effects on children's literacy outcomes. For example a randomised controlled trial (RCT) of a six week shared reading intervention for 3-4 year old children (whose carers are in receipt of government subsidies) 
showed significant improvements in the participant children's expressive language outcomes (Lonigan and Whitehurst, 1998). The study trialled different versions of the programme against a control group: a school version (where teachers read to children); a home version (where parents read to children); and a home and school combined version. The study sample was small ( $N=91)$, but it found moderate improvement effects for the programme on two expressive vocabulary ability tests $(d=.41$ and $d=.44)$ with a sub-analyses showing the largest effects for versions that featured the home reading element. A further longitudinal follow up RCT study of a 30 week shared reading programme for pre-school children also showed positive effects (Piasta et al., 2012). The STAR programme (Sit Together And Read) was delivered by teachers in 85 pre-schools $(\mathrm{N}=366)$. The evaluation found significant small to moderate effects on reading, spelling and comprehension outcomes (ranging from $d=.21$ to $d=.31$ ) compared to a control group. The effects were present at one year post-test and maintained at a two year follow up post-test. In addition, there were notable differences in the effect sizes produced between the high dose version of the programme (120 prescribed sessions of shared reading, average $d=.25$ ) compared to a low dose version (60 sessions of shared reading, average $d=.15$ ).

There have also been numerous specific research investigations into free book gifting programmes and the research base is continuing to grow. One of the most widely researched book gifting programmes is 'Bookstart', which is gifted by health visitors close to the child's first birthday (Booktrust, 2013a). Several studies by Wade and Moore, (1993; 1996; 1998 and 2000) have used quasi-experimental designs to examine the short, medium and long term impact of 'Bookstart'. This has been followed by a number of other observational, qualitative and quasiexperimental investigations (Collins et al., 2005; Hines and Brooks, 2005; Hunn, 2007; Spratt and Philip, 2007). All of these studies report positive outcomes and views among the parents, children and professionals involved with the programme (see Moore and Wade, 2003 for a review of the literature). Furthermore, these positive programme perceptions have been replicated in several other studies of international versions of book gifting programmes which have been stimulated by 'Bookstart' (Kovalik, 2010; Vanobbergena et al., 2009). However, on investigation of this literature, there are no known RCT evaluations of Bookstart making it difficult to accurately gauge the effects that this programme may be having on family reading outcomes. In addition, research studies investigating Dolly Parton's Imagination Library have also reported positive findings (Thomason, 2008). For example, one study showed $48 \%$ of kindergarten teachers $(N=320)$ and $64 \%$ of pre-Kindergarten teachers $(N=120)$ reported that students who received the Imagination Library performed "better than expected" or "much better than expected" than for students from previous classes (TBR, 2007). However, like Bookstart, there are no known RCT evaluations of this programme. 
Free book gifting also occurs as part of more complex literacy programmes and public health interventions. Often these interventions provide a suite of reading support services linked to and including the provision of free age appropriate books. For example, the 'Little Books' programme is a literacy intervention for beginning readers that has both home and school components. Teachers use a 24 week authorised language programme which is complemented by a series of bespoke reading booklets. The children receive a new booklet every week and are allowed to keep the series of books at the end of the programme. Therefore, the programme has an element of free book gifting attached to the authorised language programme. A RCT and longitudinal follow up study, over four years, was conducted on the Little Books programme (Phillips et al., 1996). In total, 18 classes from 12 schools and involving 325 kindergarteners, took part in the study (note randomisation occurred at the school level but data was analysed at the pupil level only). The study had four different groups: The first group (control) used the language programme only; the second group used the language programme and the bespoke books in both the class and at home; the third group used the books at home only with support from the school in the form of telephone calls and evening meetings; and the fourth group used the books and language programme in class only. Effect sizes for the programme on reading achievement for the treatment groups varied depending on several factors, including the measures used and the duration between the programme implementation and outcome measurement. An example of the programme effects for the home and school group ( $N=69)$ at the end of their kindergarten year (that is shortly after the programme implementation) showed an effect size increase in reading achievement of $d=.30$, compared to the control group $(\mathrm{N}=65)$. In comparison, the home only group $(\mathrm{N}=81)$ showed an effect size increase of $\mathrm{d}=.01$ compared to the control group. Overall, the results indicated that the programme had improved reading achievement but the greatest and most sustainable improvement was to be found in the home and school combined version of the programme.

Another example of a more complex intervention, which includes a free book gifting element, is the 'Reach out and Read' (ROR) programme (Reach out and Read, 2013). ROR operates in paediatric clinics where health professionals, trained in literacy support, provide advice during health consultations. Trained waiting room readers also provide reading support and doctors 'prescribe' free books to children and their families. This multi-faceted approach to improving literacy has received significant political and financial support and the programme currently operates at 5,000 sites across the US, distributing 6.5 million books per year (Reach out and Read, 2013). ROR has been investigated by numerous research studies. These studies have used a range of research designs including: qualitative (Byington et al., 2008; Diener et al., 2012; King et al., 2009); cross-sectional (Silverstein et al., 2002; Theriot et al., 2003; Weitzman et al., 2004;), and quasi-experimental investigations (Jones et al., 2000; High et al., 1998; Mendelsohn 
et al. 2001; Needlman et al., 2005; Sanders et al., 2000; Sharif et al., 2002). However, there have also been two RCTs conducted on the programme's effectiveness (Golova et al., 1998 and High et al., 2000). Both of these studies have found positive effects of the programme on literacy outcomes. A study of 135 Hispanic families (Golova et al., 1998) found that intervention parents were 10 times more likely to read to their children three days per week than control families (Odds Ratio = 10.1). The other study (High et al., 2000) looked at vocabulary test scores of 150 low income families for a ROR intervention group compared to a control group. They did not assess vocabulary scores at pre-test and thus potential differences between control and intervention groups at pre-test are not identifiable. However, using post-test scores only (means, standard deviations and sample size) the effect sizes of the programme on receptive and expressive vocabulary are considerable $(d=4.09$ and $d=2.27$ respectively.) If the results in these two studies are a true reflection of the ROR programme effects, then this programme is producing effects exceptionally large compared to those of other successful literacy interventions.

Another, randomised controlled trial evaluation was conducted on a similar clinic based literacy intervention called 'Project Read' (Fortman et al. 2003). Six clinics were randomised and the total recruited sample was $\mathrm{N}=242$ (note their analysis did not account for clustering effects). This study investigated the differential relationship between programme activities and family literacy orientation. Activities included the following elements: the family saw a volunteer reader; a doctor or nurse spoke about reading to them; they received a free book; and they received a free shared reading instruction video. The study found only one significant relationship between type of activity and family literacy orientation; namely if they had received the free video (odds ratio=2.2, $p=0.048$ ). However, the free book gifting element was not found to significantly predict literacy orientation

In conclusion, there is significant international activity in relation to book gifting utilising substantial amounts of financial and human resources. It is notable, however, that while there now exists a significant body of research on book gifting, many of these studies have not used research methods capable of producing the most robust evidence of the actual effectiveness of this type of programme in improving literacy outcomes among children and their families. In addition, there are no known peer-reviewed published evaluations of 'stand-alone' book-gifting programmes that make use of a randomised controlled trial design and only a few trials of the more complex literacy interventions that include a book-gifting element (such as 'Little Books' and 'ROR') and these studies generally do not account for the clustered nature of the data. Furthermore, the large disparity between reported effects of these trials of more complex literacy interventions (ranging from $d=.01-d=4.01$ ) make it hard to judge the expected effects 
of a programme which is typified by the book gifting element as in this study. The present study begins to address these research gaps by conducting a clustered RCT evaluation of the Bookstart+ free book gifting programme.

\section{The Bookstart+ Programme}

The Bookstart+ pack is delivered to parents/carers by health visitors during their two year visit. The primary aim of the programme noted by the provider is to inspire a love of books in children and their families. The pack contains the following items:

- A nylon satchel style bag

- Two books

- A colouring book

- A pack of crayons

- A bedroom frieze

- A set of 'Bookplate stickers' saying, 'This book belongs to .....'

- A list of recommended toddler books

- A guide for parents entitled 'More Things to do with books!'

More information on the Bookstart+ pack is available from the Booktrust website (Booktrust, 2013b).

Usual practice would be to include some sign-posting to the public library in all Bookstart+ packs including library leaflets and information. However, it is important to note that this was not done in relation to the packs distributed in the present trial where each pack did not include any information or leaflets on the local library. Also, 73.3\% of families in the analysis had previously received a Booktrust Bookstart pack. This pack is similar to the Bookstart+ pack, but gifted on the first year health visit, that takes place one year earlier. The health visitor receives no formal training on how to gift the year one Bookstart pack.

The health visitors in the current study did receive training on how to gift the Bookstart+ pack including how to conduct a short demonstration aimed at encouraging positive family reading attitudes. The training comprised of a Booktrust co-ordinator attending all of the health visitor area meetings in the Northern Ireland Health and Social Care Trust and providing a 30 minute presentation followed by a question and answer session. All health visitors were also provided with an administration pack describing how to gift the packs, and further background on the programme. 
The key elements of the Bookstart+ coordinator's presentation were:

- To give the pack with priming statements that encourage parents to share books more often with their child;

- Open one of the books and give it to the child, so that the parent can see the child's reaction;

- Deliver the following key messages:

- Children need stories as an essential part of their development and should be part of their daily routine from as early as possible;

- Sharing stories helps build loving relationships and all family members can join in;

- Parents can learn tips from the material included in the pack;

- Babies and toddlers should be encouraged to join the library. It is free to join the library and there are no fines on books taken out on children's tickets.

Overall, this is a low cost programme. The cost per child of the Bookstart+ programme is between $£ 3.45$ and $£ 6.00$ (between $\$ 5.41$ and $\$ 9.40$ ) depending on the number of children being gifted packs. There has been a recent social return on investment analysis conducted on the Bookstart programme which found an overall return on investment of 1:25 (Just Economics, 2010).

\section{Methodology}

\section{Research Design}

The research design consisted of a cluster randomised controlled trial involving 460 families (with a two-year-old child) from the client lists of 115 health visitors in four geographical areas of the north east of Northern Ireland in the UK. Each health visitor was assigned four families by the health visitor service manager. The four families assigned to each health visitor were then randomly allocated to intervention or control groups. As such each health visitor therefore had two control families and two intervention families in the study. In this sense, the randomisation was individually randomised but clustered by health visitor.

The research team conducted the randomisation and provided these details to the Health Visitors through the Health Visitor Manager. During a family visit the health visitors asked parents for consent to take part in the research. If the parents consented they were asked to fill in a pre-test questionnaire. On completion of the questionnaire the health visitor informed the parent of which group they were in (control or intervention). It was not possible for parents to fill out the pre-test before randomisation by the researchers as there was only one yearly visit 
to each family but they were unaware of their allocated group until after completion of the pretest questionnaire. The health visitors then gifted the Bookstart+ packs to the intervention families only and provided the priming demonstration about shared reading. The health visitors provided only standard services to the control families. The control families were provided instructions on how to obtain the packs and support materials after the intervention period and post-testing was completed.

The study employed an intention to treat design. Therefore, no families were moved between the control and intervention groups. Also, the participation level of any particular family in the programme was not considered in the analysis. Rather, all consenting families that provided pre- and post-test data were included in the analysis regardless of their engagement with the programme.

\section{Procedure}

The intervention took place over a three month period. Pre-testing was undertaken in March 2010 and the post-tests were conducted in May 2010. All pre-test data collection was conducted by the health visitors. Post-test data collection was carried out by the research team by mail or over the telephone. In all cases, a standardised questionnaire was used, which was developed by the research team in consultation with the service provider.

\section{Outcome Measures}

This study focused on three main outcomes which were felt to reflect the core aim of the intervention, namely: 'to inspire a love of books in children and their families'. These outcome measures were developed in partnership with the service provider before the trial took place. For the purposes of this present evaluation, an outcome is defined as a real and discernible change in attitudes and/or behaviour that has occurred as a direct result of receiving the Bookstart+ intervention. The resultant outcomes were:

- An improvement in parental attitudes to reading and books

- An improvement in parents' attitudes to sharing and reading books with their child

- An increase in family use of the library

Each of the outcomes was measured by a composite mean score from several items within the research questionnaire as shown in Table 1. The last column in Table 1 is the Cronbach's Alpha score for each outcome measure. The Alpha scores for the major outcome variables suggest that all three measures are sufficiently reliable. In terms of validity, the measures would all appear to have good face validity and a factor analysis on each of the three measures in turn 
indicated that these measures also have good construct validity, with all three being unidimensional.

In addition to these items, several demographic variables were collected through the research instrument for exploratory analysis including: family income (a proxy measure for socioeconomic status); educational attainment; numbers of other children in the home; the geographical area family lived in; and whether they had previously received a Bookstart pack before (the one year health visit pack).

\section{[TABLE 1 ABOUT HERE]}

\section{Sample}

An a priori sample size calculation indicated that a sample of $180-395$ would be required to detect significant effects in the range of $d=.2$ to .3 at a power of $80 \%$. As can be seen in Figure 1 of the initial 460 families randomised, the research team received 341 pre-test questionnaires (74.1\%) from these families. The reasons for attrition at this point were: the health visitor did not visit a particular assigned family for some reason; the health visitor did not gain consent from an assigned family; or the health visitor did not return a completed questionnaire to the research team. Moreover, only 203 families that had completed the pre-test also returned a post-test questionnaire; making up $59.5 \%$ of those who had previously completed the pre-test questionnaire and just $44.1 \%$ of the original total number of families identified for the study. Returning to the sample size calculation it can be seen that the final analysis sample of 203 was within the range of 180-395 specified by the calculation.

\section{[FIGURE 1 ABOUT HERE]}

As indicated in Figure 1 there was substantial attrition during the various stages of testing. This was due to the accumulation of attrition firstly by unreturned pre-test questionnaires compounded by parents not returning post-test questionnaires. Overall, attrition was slightly higher in the intervention group (5\%). The attrition could have potentially introduced bias into the trial. To explore this, the characteristics of parents in the control and intervention groups at pre-test were compared. This was done only for those families who remained in the trial until the end, and thus for whom full data was gathered and analysed for programme effects. The comparison scores included: their mean scores on the three outcome variables; their socioeconomic status; levels of parental education; and whether they had received a Bookstart pack before (that is, the pack gifted at the child's year one health visit). As shown in Table 2, it was 
found that the two groups were well matched with no statistically significant differences in relation to any of these six variables.

\section{[TABLE 2 ABOUT HERE]}

A further exploration of attrition utilised an analysis of differential attrition effects. This analysis explored differences on pre-test variables between those who chose to return post test questionnaires and those who chose not to return post-test information. There were significant differences between these two groups on two variables, which were as follows: pre-test child reading $(t=-3.00, d f=339, p<.01)$; and socio-economic status $(t=-2.04, d f=174, p=.04)$. The implications of this are discussed in the limitations section below.

\section{Statistical Analysis}

The main analysis of effects produced by the intervention, on the three outcomes identified, was conducted using multi-level regression models with families (level 1) clustered within health visitors (level 2). The models included the outcome variable (post-test score for each outcome) and the two covariates: group (control or intervention) and pre-test score (for the particular outcome). Alongside this, further pre-specified multi-level exploratory analyses were undertaken to assess whether Bookstart+ was having differential effects on parents depending upon: their socio-economic status; their levels of educational attainment; the number of other children they have in the family; the geographical area where they live; and whether they had previously received a Bookstart pack. This further analysis involved developing the main models by including appropriate interaction terms based on these demographic indicators.

Effects were calculated using the models described above to estimate the post-test mean scores for the intervention and control groups once pre-test scores were controlled for. The specific effect size measure used here was the standardised mean difference calculated as the difference in these two mean scores divided by the pooled standard deviation for the post-test scores for both groups (i.e. Cohen's d), and after controlling for any differences in pre-test scores.

\section{Results}

The Main Effects of Bookstart+ on Outcomes

Table 3 summarises the findings of the trial in relation to the effects of the Bookstart+ intervention on the three outcome variables. The standardised effect sizes associated with the intervention in relation to each of the three outcomes are provided and allow for direct 
comparisons of the effects of Bookstart+ with some of the other results from RCTs of reading interventions previously highlighted in the literature.

\section{[TABLE 3 ABOUT HERE]}

In relation to the first outcome, there was evidence of a positive effect of Bookstart+ on parents' attitudes to their own reading, with the mean score of parents in the intervention group on the parent attitudes scale being higher $(m=3.26, s d=.56)$ than that of parents in the control group ( $m=3.12$, $s d=.61)$, which represented a significant effect.

In relation to the second outcome, of parents' attitudes to their child reading, it can be seen that there is some potentially encouraging signs of improvement with the mean score of parents in the intervention group on the child reading attitudes scale $(m=3.60, s d=.36)$ being marginally higher than that of parents in the control group $(m=3.57, s d=.40)$. However, given the small size of this effect $(d=+.09)$, this difference was not statistically significant and therefore cannot be reported as a reliable finding.

For the third outcome, it can be seen from Table 3 that there is some evidence, approaching statistical significance, of a negative effect $(d=-.160)$ on families, with those in the intervention group showing a reduction in their mean score on the library use scale $(m=1.07, s d=1.06)$ in comparison with those in the control group $(m=1.25, \mathrm{sd}=1.18)$.

In addition to the analysis of main effects, further exploratory analyses examining other background variables were conducted. This was undertaken by developing the basic regression models by adding in an interaction term between the contextual variable of interest and group membership. In relation to all three outcomes, however, no evidence was found of such differential effects. In other words, the effects of Bookstart+ reported above tended to be similar regardless of family background characteristics, namely: socio-economic background; parents with differing levels of educational attainment; parents with differing numbers of other children in the home; parents from differing geographical areas; and whether they had previously received a Bookstart pack.

\section{Discussion}

\section{Summary of Results}

Findings from this randomised controlled trial provide evidence that Bookstart+ has achieved a positive impact on parents' attitudes towards reading. Indeed, and as reported earlier in relation to the review of existing evidence, the size of the effect found in relation to this 
$(d=+.24)$ is in the range of what would be expected for a low-intensity, low-cost intervention such as this. There were also some potentially encouraging signs of positive change in parents' attitudes to their child reading $(\mathrm{d}=+.09)$, although this change was not statistically significant and therefore cannot be reported as a reliable finding in its own right.

The one potentially negative effect occurred in relation to the reduced interaction with the local library by parents who received the Bookstart+ pack. This effect was approaching statistical significance and is thus a matter of concern. One plausible explanation is that being given books directly in the home could reduce the need for parents, in the short-term (over the three month implementation period), to visit a local library. As such, while there may initially be a negative effect this could conceivably turn into a neutral or positive effect in the medium to longer-term as the initial receipt and use of such books increase the parents' motivation to seek out more from their local libraries and elsewhere. Unfortunately, it is not possible to assess this from the evidence generated from this present trial as no longitudinal follow up study was conducted. In addition, the research literature does not provide any further explanation as there are no known rigorous trials of book-gifting only interventions and thus no estimates of the importance of library information in packs.

\section{Study Limitations}

There are a several limitations of this study. The first is that there was a high attrition rate. A total $43.9 \%$ of families completed all stages of the testing. However, no significant differences between the two fully completing groups at pre-test were found which reduces the possible impact of this attrition on the validity of the findings. The further exploration of differential attrition effects also showed significant differences between those who completed all parts of the study and those who did not return post-test questionnaires across the intervention and control groups. These differences were linked to socio-economic status and child/parent shared reading. Possible explanations for these links are that parents who did not engage in the programme may not have wished to reply to a questionnaire that asked about this specific issue. Furthermore, socio-economic status may have been a limiting factor in returning a postal questionnaire in terms of differing dispositions either towards participation in the research and/or the issue of reading. It is possible that these attrition effects may have limited the external validity of this study in terms of the generalisability of the results. The identified effects may be for a group who are likely to be more affluent and already engaged in some shared reading. However, it is not possible to identify if the effects of the study would have been greater or smaller if the sample had increased heterogeneity. This would require an enhanced study with additional strategies for ensuring the return of post-test questionnaires from all families involved. 
A further limitation is the specificity of the measures. As there is limited prior experimental research on book gifting programmes, the measures were chosen on face validity thus potentially impacting on the specificity matching principal of linking measures to outcomes (Swann et al., 2007). However, the measures used did identify effects with a reasonable degree of reliability and validity.

Lastly, the study was a small trial of impact only and as a result it did not explore implementation practices of the health visitors in terms of their fidelity to the programme instructions. For example some health visitors may have delivered the intervention with more fidelity to the administration manual than others. Similarly, the quality of delivery may have varied between the four visits for each individual health visitor. Furthermore, the fact that health visitors worked with both control and intervention families may have had a contaminating effect on an individual's implementation practices. In light of all these potential influences on implementation quality by health visitors it would have been useful to control for implementation quality in the statistical models. However, it was beyond the scope of this study to collect these data and this therefore remains a significant limitation in the current trial.

\section{Implications for Practice}

There are two key implications for practice that flow from this study. These practice suggestions are based on inferences using the effects found in the study. Firstly, there is the need to put into place strategies that mitigate the short-term negative effect on library usage among families that received the gift-pack. In this regard, it is worth noting that in the Bookstart+ packs sent out for the present trial, none actually contained inserts providing details and information on local libraries for the parents. It is difficult to assess the extent to which this was a contributory factor. However, it does suggest the need to ensure that such promotional information is included in all packs before they are distributed. It may also be worthwhile having local libraries increasing the numbers of events that are targeted at parents with young children and ensuring that these are clearly advertised in gift-packs and/or any follow-up correspondence.

Secondly, this research has demonstrated that changing parents' attitudes to reading is one of the most powerful effects of the Bookstart+ programme. Furthermore, the programme showed signs of having effects on other environmental (library usage) and social outcomes (shared reading). When these findings are considered alongside the fact that the activities of the programme include an educational service provider, health professionals, parents and children, it demonstrates how book gifting can be a useful tool in developing integrated services. In other 
words, book gifting can help infuse literacy promotion into other family services (in this case health services) which could potentially have an effect on a range of family outcomes. Indeed other Booktrust programmes and public health interventions, such as Reach Out and Read, utilise variations of this integrated model by being gifted in both educational, health and social care settings. However, given the very small, and non-significant, impact on family reading practices, this study suggests that further work is needed to develop an integrated approach to translating the positive impact on parents' attitudes to reading to an increase in shared reading with their children.

\section{Conclusion}

This study suggests that book gifting, as an intervention type, can have a reasonable positive effect on family reading attitudes, even given the low cost and low intensity of the intervention. Therefore, the results of this study, combined with previous RCT evaluations of other programmes that include book gifting elements, such as 'Little Books', 'Reach Out and Read' and shared reading development such as STAR (Sit Together And Read), would encourage the development and expansion of such programmes.

A methodological contribution of this study is that it provides evidence that randomised controlled trials are a useful tool for evaluating the effectiveness of book gifting programmes in relation to family reading outcomes. In addition, these emerging positive results suggest that more comprehensive randomised controlled trial evaluations of book gifting interventions should be undertaken, using larger samples and possibly carried out on a national or international basis. Such trials would allow for the development of more detailed and specific outcome measures and also a more comprehensive analysis of the potential mediating influences of key contextual factors. The trials would also allow the effectiveness of the interventions to be tested after any refinements are made, which are in line with the practice development suggestions made above. Lastly, in relation to library use, it could test the longerterm effects of the pack if an appropriate longitudinal component was added.

In summary, the implications of this study for policy and practice are:

- Book gifting programmes can be a useful tool for integrating services allowing family service commissioners to integrate the delivery of educational and health services

- Book gifting programmes can be a useful way to improve parents' attitudes to books and reading in the home, although further work is needed in terms of ensuring that this translates into increased family practices in the home 
- Book gifting programme providers should be aware of the potential impact book gifting has on short-term library usage

- More systematic and rigorous evaluations of book gifting programmes is required in order to provide a greater evidence base in terms of effective programme delivery. 


\section{References}

Booktrust (2013a), “Bookstart Packs”, available at: http://www.bookstart.org.uk/bookstart-packs/ (accessed 26 August 2013)

Booktrust (2013b), "Bookstart+ Packs", available at: http://www.bookstart.org.uk/bookstartpacks/bookstart-packs-in-the-uk/northern-ireland/bookstart-plus/ (accessed 26 August 2013)

Bus, A.G., ljzendoorn, M.H. and Pellegrini, A.D. (1995), "Joint book reading makes for success in learning to read: a meta-analysis on intergenerational transmission of literacy", Review of Educational Research, Vol. 65 No. 1, pp. 1-21.

Byington, C.L., Hobson, W.L., Olson, L., Torres-Nielsen, G., Winter, K., Ortiz, K.A. and Buchi, K.F. (2008), "The good habit of reading (el buen habito de la lectura): Parental reactions to an enhanced Reach Out and Read programme in a clinic for the underserved", Journal of Health Care for the Poor and Underserved, Vol. 19, pp. 363-368.

Collins, F. M., Svensson, C., and Mahony, P. (2005), Bookstart: Planting a Seed for Life, Booktrust, London.

Diener, M.L., Hobson-Rohrer, W., and Byington, C.L. (2012), "Kindergarten readiness and performance of Latino children participating in Reach Out and Read" Journal of Community Medicine and Health Education Vol. 2 No. 3, pp. 1-7.

Fortman, K.K., Fisch, R.O., Phinney, M.Y. and DeFor, T.A. (2003) "Books and Babies: ClinicalBased Literacy Programs", Journal of Pediatric Health Care, Vol. 17 No. 6, pp. 295-300.

Golova, N., Alario, A.J., Vivier, P.M., Rodriguez, M., and High, P.C. (1998), "Literacy promotion for Hispanic families in a primary care setting: A randomised controlled trial", Pediatrics, Vol. 103, pp. 993-997.

Hines, M. and Brooks, G. (2005) Sheffield Babies Love Books: An Evaluation of the Sheffield Bookstart Project, University of Sheffield, Sheffield.

High, P.C., LaGasse L., Becker, S., Ahlgren, I., and Gardner, A. (2000), "Literacy promotion in primary care pediatrics: can we make a difference?", Pediatrics, Vol. 104, pp. 927-934. 
High, P., Hopmann, M., LaGasse, L. and Linn H. (1998), "Evaluation of a clinic-based program to promote book sharing and bedtime routines among low-income urban families with young children", Archives of Pediatrics and Adolescent Medicine, Vol. 15, pp. 459-465.

Hunn, C. (2007), Is the Bookstart Programme an effective way to encourage shared reading experiences between parents and children?, Unpublished Thesis University of Plymouth, Plymouth.

Jones, V.F., Franco, S.M., Metcalf, S.C., Popp, R., Staggs, S., and Thomas, A.E. (2000), "The value of book distribution in a clinic-based literacy intervention programme", Clinical Pediatrics, Vol. 39, pp. 535-541.

Just economics (2010), Bookstart 2009/10: A Social Return on Investment (SROI) Analysis. Booktrust, London.

King, T.M., Muzaffar, S., and George, M. (2009), "The role of clinic culture in implementation of primary care interventions: The case of Reach Out and Read", Academic Pediatrics, Vol. 9 No. 1, pp. 40-46

Kovalik, C. (2010), "Evaluation des Projekts - Buchstart Schweiz", available at: http://www.leseforum.ch/fr/myUploadData/files/2010 3 Kovalik.pdf (accessed 05 April 2013)

Lonigan, C. J., and Whitehurst, G. J. (1998) "Relative efficacy of parent and teacher involvement in a shared-reading intervention for preschool children from low-income backgrounds", Early Childhood Research Quarterly, Vol. 13 No. 2, 263-290.

Mendelsohn, A.L., Mogiler, L.N., Dreyer, B.P., Forman, J.A., Weinstein, S.C., Broderick, M., Cheng, K.J., Magloire, T., Moore, T. and Napier, C. (2001), "The impact of a clinic-based literacy intervention on language development in inner-city preschool children", Pediatrics, Vol. 107 No. 1, pp. 130-134.

Moore, M. and Wade, B. (2003), "Bookstart: a qualitative evaluation", Educational Review, Vol. 55 No. 1, 3-13.

Needlman, R., Fried L.E., Morley, D.S., Taylor, S. and Zuckerman B. (1991), "Clinic-based intervention to promote literacy. A pilot study", American Journal of Diseases of Children, Vol. 145, pp. 881-884. 
Needlman, R., Toker, K.H., Dreyer, B.P., Klass, P., and Mendelsohn, A.L. (2005), "Effectiveness of a primary care intervention to support reading aloud: a multicenter evaluation", Ambulatory Pediatrics, Vol. 5, pp. 209-215.

Piasta, S. B., Justice, L. M., McGinty, A. S., \& Kaderavek, J. N. (2012), “Increasing young children's contact with print during shared reading: Longitudinal effects on literacy achievement" Child development, Vol. 83 No. 3, 810-820.

Phillips, L. M., Norris, S. P., and Mason, J. M. (1996), "Longitudinal effects of early literacy concepts on reading achievement: A kindergarten intervention and five-year follow-up", Journal of Literacy Research, Vol. 28 No., 1, pp. 173-195.

Sharif, I., Rieber, S., and Ozuah, P. O. (2002), "Exposure to Reach Out and Read and vocabulary outcomes in inner city pre-schoolers", Journal of the National Medical Association, Vol. 94 No. 3, pp. 171-177.

Silverstein, M., Iverson, L., and Lozano, P. (2002), “An English-language clinic-based literacy programme is effective for a multilingual population", Pediatrics, Vol. 109 No. 5, pp. 76-82.

Spratt, J. and Philip, K. (2007), An Appraisal of Bookstart in Sighthill, Edinburgh, Bookstart Scotland.

Swann, W.B., Jr., Chang-Schneider, C., and McClarty, K. (2007), "Do our self-views matter? Selfconcept and self-esteem in everyday life", American Psychologist, Vol. 62, pp. 84-94.

TBR (2007), "Tennessee Board of Regents: Tennessee's Imagination Library Improves School Preparedness", available at: http://uwcentralcoast.org/PDF/BooksFromBirthResearch.pdf (accessed 05 April 2013)

Theriot, J.A., Franco, S.M., Sisson, B.A., Metcalf, S.C., Kennedy, M.A., and Bada, H.S. (2003), "The impact of early literacy guidance on language skills of 3-year-olds", Clinical Pediatrics, Vol. 42, pp. 165-172.

Thomason, G. B. (2008), The impact of the Ferst Foundation for Childhood Literacy on the home literacy environment, Unpublished doctoral dissertation Liberty University, Lynchburg, VA. 
Vanobbergena, B., Daemsa, M. and Van Tilburg, S. (2009), "Bookbabies, their parents and the library: an evaluation of a Flemish reading programme in families with young children", Educational Review, Vol. 61 No. 3, pp. $277-287$.

Wade, B. and Moore, M. (1993), Bookstart, Book Trust, London.

Wade, B. and Moore, M. (1996), “Children's early book behaviour”, Educational Review, Vol. 48, pp. 283-288.

Wade, B. and Moore, M. (1998), "An Early Start with Books: Literacy and Mathematical Evidence from a Longitudinal Study", Educational Review, Vol. 50 No. 2, pp. 135-45.

Wade, B. and Moore, M. (2000), "A sure start with books," Early Years, Vol. 20 No. 2, pp. 39-46.

Weitzman, C.C., Roy, L., Walls, T., and Tomlin, R. (2004), “More evidence for Reach Out and Read: A home-based study." Pediatrics, Vol. 113, pp. 1248-1253. 
Table 1: Major outcome variables and contributing items with Cronbach's Alpha

\begin{tabular}{|c|c|c|}
\hline Outcome & Items & Alpha \\
\hline \multirow[t]{2}{*}{ Parent Attitudes } & I like reading & \multirow[t]{5}{*}{.80} \\
\hline & I find it hard to finish books & \\
\hline \multirow{3}{*}{$\begin{array}{l}\text { (parental attitudes } \\
\text { to reading and } \\
\text { books) }\end{array}$} & It is important for me to be a good reader & \\
\hline & How often do you read books? & \\
\hline & How often do you buy books for yourself? & \\
\hline \multirow[t]{2}{*}{ Child Reading } & How often do you or your partner read to your child? & \multirow[t]{4}{*}{.69} \\
\hline & Do you have books for babies or toddlers in the home? & \\
\hline \multirow{2}{*}{$\begin{array}{l}\text { (parent and child } \\
\text { attitudes to } \\
\text { reading and } \\
\text { sharing books) }\end{array}$} & What is your child's attitude towards books? & \\
\hline & What is your attitude towards reading with your baby/toddler? & \\
\hline \multirow[t]{2}{*}{ Library Use } & Are you or your child/children a member of your local library? & \multirow[t]{3}{*}{.67} \\
\hline & $\begin{array}{c}\text { Have you, for yourself or on behalf of a child, borrowed a book } \\
\text { or other material from a local library in the last } 3 \text { months? }\end{array}$ & \\
\hline $\begin{array}{l}\text { (family interaction } \\
\text { with the library) }\end{array}$ & $\begin{array}{l}\text { Have you or your partner attended any baby or toddler- } \\
\text { oriented events at a local library? }\end{array}$ & \\
\hline
\end{tabular}


Table 2: Means, standard deviations and significance of difference on variables at pre-test only for families for whom pre-test and post-test data were collected ( $n=203)$

\begin{tabular}{|c|c|c|}
\hline Outcome Variable & Summary Statistics & Statistical Significance \\
\hline Parent Attitudes Intervention & $m=3.94, s d=.73$ & \multirow[t]{2}{*}{$p=.324, t=.988, d f=200$} \\
\hline Parent Attitudes Control & $\mathrm{m}=3.85, \mathrm{sd}=.68$ & \\
\hline Child Reading Intervention & $\mathrm{m}=3.55, \mathrm{sd}=.41$ & \multirow[t]{2}{*}{$p=.688, t=.403, d f=201$} \\
\hline Child Reading Control & $m=3.57, \mathrm{sd}=.41$ & \\
\hline Library Usage Intervention & $\mathrm{m}=1.08, \mathrm{sd}=1.02$ & \multirow[t]{2}{*}{$p=.621, t=.495, d f=197$} \\
\hline Library Usage Control & $\mathrm{m}=1.15, \mathrm{sd}=1.12$ & \\
\hline Socio-economic Status Intervention & $m=5.66, s d=1.84$ & \multirow[t]{2}{*}{$p=.405, t=.836, d f=110$} \\
\hline Socio-economic Status Control & $m=5.95, s d=1.80$ & \\
\hline Parent Education Intervention & $\mathrm{m}=4.57, \mathrm{sd}=1.19$ & \multirow[t]{2}{*}{$p=.912, t=.111, d f=175$} \\
\hline Parent Education Control & $m=4.59, \mathrm{sd}=1.28$ & \\
\hline Bookstart Pack Before Intervention & $75.5 \%$ & \multirow[t]{2}{*}{$p=.617$, chi-square $=.251, d f=1$} \\
\hline Bookstart Pack Before Control & $78.5 \%$ & \\
\hline
\end{tabular}


Table 3: Summary of a Multi-level Model of Main Effects of the Programme for Families: Including a Grouping Variable for Health Visitor.

\begin{tabular}{|c|c|c|c|c|}
\hline \multirow[t]{2}{*}{ Outcome } & \multicolumn{2}{|c|}{$\begin{array}{c}\text { Post-Test Mean Scores* } \\
\text { (with Standard Deviations) }\end{array}$} & \multirow{2}{*}{$\begin{array}{c}\text { Effect Size } \\
\text { [95\% Confidence } \\
\text { Interval] }\end{array}$} & \multirow[t]{2}{*}{ Significance } \\
\hline & Control & Intervention & & \\
\hline $\begin{array}{l}\text { Parent attitudes to their own } \\
\text { reading }\end{array}$ & $\begin{array}{l}3.12 \\
(.61)\end{array}$ & $\begin{array}{l}3.26 \\
(.56)\end{array}$ & $\begin{array}{c}+.24 \\
{[+.05,+.43]}\end{array}$ & $p=.01$ \\
\hline $\begin{array}{l}\text { Parent attitudes to reading } \\
\text { with their child }\end{array}$ & $\begin{array}{l}3.57 \\
(.40)\end{array}$ & $\begin{array}{l}3.60 \\
(.36)\end{array}$ & $\begin{array}{c}+.09 \\
{[-.07,+.24]}\end{array}$ & $p=.28$ \\
\hline Extent of library use & $\begin{array}{c}1.25 \\
(1.18)\end{array}$ & $\begin{array}{c}1.07 \\
(1.06)\end{array}$ & $\begin{array}{c}-.16 \\
{[-.32, .00]}\end{array}$ & $p=.06$ \\
\hline
\end{tabular}

*Adjusted to control for pre-test scores. 


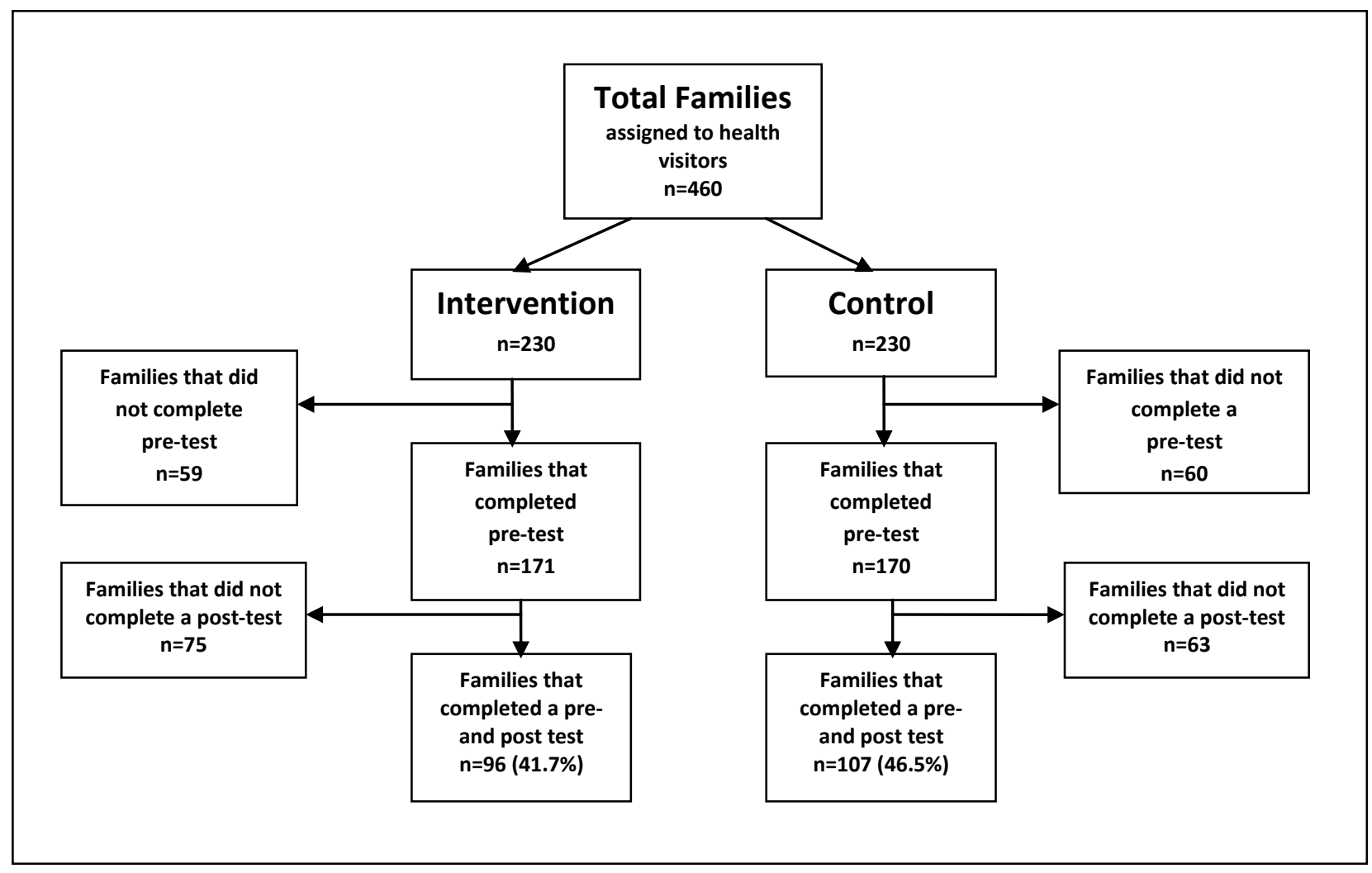

